\title{
G. J. Derbyshire: Stand up for Autism: A Boy, a Dog, and a Prescription for Laughter
}

\author{
Jessica Kingsley Publishers, Philadelphia, 2010, 140 pp., ISBN 978-1-84905-099-9, \\ $\$ 14.95$ (paper)
}

Felicity Ruth Butterly

Published online: 19 August 2011

(C) Springer Science+Business Media, LLC 2011

The book was found to be readable, quirky, and resonant with the anecdotal literature currently being published on families perspectives of living with autism. It is recommended as a resource for trainee researchers and clinicians wishing to communicate effectively with families who have a child diagnosed with autism.

Stand up for Autism is a book written by a mother, Georgina Derbyshire, about her own experiences of having a young son with autism. The author speaks very much as a mother seeking some comic relief in stressful situations, whose power as a stressor lies in their everyday occurrence. She describes the esoteric weirdness of conversations with carpet cleaners (Don't knock any Lego over!) to the daily reports from school attendance (A bad day... Another bad day...Yet another bad day). It is a readable detailed narrative of a parent's experience, not just a mother's, and that experiences' meaning to other relationships in Derbyshire's life. Using examples from her life with her son, Derbyshire addresses basic questions that families/parents might themselves go through: Should I explain my child to strangers? How do I manage my autistic child on a plane? How do I get sleep?

The author easily explores these problems and others with little vignettes from her life and direct quotes from conversations she and/or her son are involved in. In this way, the book provides some risk assessment practices in managing novel situations. The ordering of the stories Derbyshire recalls in the book make up each chapter but offer no particular schedule. And it is the second story,
'Barking at parents and toddlers', that gives us, the readers that bit of insight that perhaps overall the collection might have missed as a unit. This story tackles the "what is normal' paradigm that parents often come across when their children with autism get the public judgement treatment. And while, yes, the autistic spectrum is a handle with care area, as is any vulnerable population, crucially this story reveals a strength that should be associated with parents of children with autism and with the children themselves.

Overall, this book is not essential reading for people working within autism. As a book viewed in a professional journal, it should be noted that the book is not a parents' guide to accessing services or seeking diagnosis for their children. Its usefulness as a practitioner's tool is limited. What it does is broaden thinking around parents' of children with autism and indeed autism itself. Therefore, for students or novice researchers preparing to interview parents of children with autism or even people with autism themselves, and for trainee clinicians who need to communicate effectively with such parents on a regular basis, reading this book may be a useful addition to their training.

\section{Reference}

Derbyshire, G. J. (2010). Stand up for autism: A boy, a dog, and a prescription for laughter. Philadelphia, USA: Jessica Kingsley Publishers.
F. R. Butterly $(\bowtie)$

Coventry University, Coventry, UK

e-mail: butterlf@uni.coventry.ac.uk

URL: http://researchinassistancedogs.wordpress.com 